\title{
EREBEA
}

\author{
Revista de Humanidades \\ y Ciencias Sociales \\ NúM. 6 (2016), pp. 197-225 \\ ISSN: 0214-0691
}

\section{De historiador de la Conguista a icono de la Hispanidad: R. B. Cunninghame Graham como mediador Cultural}

\author{
David Jiménez Torres \\ Universidad Camilo José Cela
}

\section{RESUMEN}

Robert Bontine Cunninghame Graham fue uno de los mediadores culturales más importantes entre Espańa y Reino Unido de finales del siglo XIX y principios del siglo XX. Este trabajo aborda tres facetas distintas de su labor de mediación: su faceta como escritor de libros de historia y relatos breves de temática hispánica, su función de nexo social entre varias figuras españolas y británicas, y el estatus que él mismo llegó a adquirir en Reino Unido como icono de una suerte de hispanidad. El objetivo es, por un lado, aumentar nuestro conocimiento de las dinámicas de relación cultural que existían entre España y Reino Unido durante la época en cuestión. Por otro lado, obtendremos una impresión más amplia acerca de las muchas formas en que una persona puede ejercer la mediación cultural entre países, al igual que las motivaciones que pueden subyacer a esta mediación.

Palabras Clave

Cunninghame Graham; cultura; España; Reino Unido; mediador.

Fecha de recepción: 30 de agosto de 2016 Fecha de aceptación: 15 de sept. de 2016

\section{Abstract}

Robert Bontine Cunninghame Graham was one of the most significant intermediaries in the cultural relationships between Spain and the UK at the end of the 19th century and the beginning of the 20th. This essay analyses three different aspects through which he carried out this mediating role: first, his authorship of a number of history books and short stories centred on the Spanish-speaking world; second, his role as a social nexus between a number of Spanish and British figures; third, the role he came to occupy in the United Kingdom as an icon of the Spanish-speaking world and some qualities associated with it. The aim is, on the one hand, to expand our knowledge of the dynamics of cultural exchange that existed between Spain and the United Kingdom during these years. More widely, we will observe the many ways in which one individual could mediate between two countries and their cultures, as well as the motivations he may have had for doing so.

\section{KeYwords}

Cunninghame Graham; culture; Spain; United Kingdom; mediator. 

Los mediadores ocupan un papel fundamental en las relaciones culturales entre países, sobre todo en aquellos contextos en los que la iniciativa estatal o comercial no está presente, o se queda corta a la hora de establecer instituciones efectivas de intercambio. Los mediadores entran a ocupar este vacío y, en ocasiones, pueden acabar convirtiéndose en una suerte de polos de intercambio sostenido, sea por la longevidad de su desempeño o por su imbricación en instituciones más tradicionales (editoriales, revistas, organismos gubernamentales, museos, instituciones educativas). Sin embargo, la multitud de vertientes distintas que puede tener esta labor de mediación hace que su figura adquiera una gran complejidad. Si bien, y como señala la historiadora Raquel Sánchez García, podemos entender al mediador en primera instancia como "aquel individuo que ejerce el papel de comunicador de conocimientos entre distintas realidades culturales", la riqueza y densidad simbólica de la estructura del conocimiento cultural hace que su labor no se restrinja a una mera transmisión material (por ejemplo, en traducciones, exposiciones... $)^{1}$. Son de suma importancia también otras funciones de mediación, como la social o incluso -en ciertos casos- la icónica. Igualmente importante es comprender las razones por las cuales un individuo se podía acabar prestando a ejercer esta labor de mediación, y hasta qué punto la misma podía servir de apoyo a proyectos políticos o personales.

Este trabajo versa precisamente sobre un importante mediador cultural entre España y Reino Unido durante las primeras décadas del siglo XX, y alguien que desempeñó esta faceta de distintas formas: Robert Bontine Cunninghame Graham (1852-1936). Me centraré en tres dimensiones a través de las cuales Cunninghame Graham facilitó y dio forma a las relaciones culturales hispano-británicas de su época: la literaria, la social y la icónica. Esto es, examinaré en primer lugar su faceta de escritor en lengua inglesa sobre la historia y la cultura españolas; en segundo lugar, abordaré su función de nexo entre las intelectualidades españo-

1 La definición está extraída de Raquel Sánchez García, "Presentación. Circulación de ideas y transferencias culturales: España y Europa en el siglo XIX", en Hispania Nova, n 14 (2016). Este trabajo, al igual que el dossier incluido en el mismo número de la revista, aporta una bibliografía actualizada de reflexiones metodológicas acerca de las transferencias culturales y el papel que en las mismas desempeñan los mediadores. También hay reflexiones interesantes al respecto en Alison Sinclair, Trafficking Knowledge in Early Twentieth-Century Spain: Centres of Exchange and Cultural Imaginaries. Woodbridge: Tamesis, 2009. 
la y británica; y finalmente analizaré su dimensión como una suerte de icono de la Hispanidad en el Londres post-victoriano. Constataremos así tanto la riqueza de la labor mediadora de este personaje como la bidireccionalidad de la misma, al influir tanto en la imagen que tenían los británicos acerca de España como en el conocimiento que tuvieron los espańoles acerca de Reino Unido. También resaltaré a lo largo del trabajo la labor de su esposa, Gabriela Cunninghame Graham, que en muchos aspectos fue complementaria a la de su marido.

\section{ARISTÓCRATA, REVOLUCIONARIO, ESCRITOR}

Un repaso a la vida de Cunninghame Graham bien podría comenzar por lo que escribió Joseph Conrad acerca de quien fue su buen amigo: "when I think of Cunninghame Graham, I feel as though I have lived all my life in a dark hole without seeing or knowing anything" 2 . Efectivamente, es difícil resumir hasta qué punto la vida de Graham fue una hiperactiva sucesión de aventuras, viajes e iniciativas. Nacido en el seno de una familia de la aristocracia escocesa, Graham recibió una educación privilegiada en Harrow y en Bruselas. También conoció pronto el español, ya que su abuela era originaria de Cádiz. Al terminar sus estudios decidió viajar a América en busca de aventuras, pasando allí una larga temporada en la que ejerció de maestro de esgrima en México, de ganadero en Tejas y de gaucho en Argentina ${ }^{3}$.

La muerte de su padre en 1883 y la preocupante situación económica en la que dejó a la familia forzaron su regreso a Reino Unido. Fue entonces cuando el joven Cunninghame Graham comenzó a mostrar interés por la política, en la que siempre se mostró muy influido por el socialismo medievalista y estetizante de William Morris. Graham se afilió al Partido Liberal y en 1886 fue elegido diputado con un programa que incluía el sufragio universal, la abolición de la Cámara de los Lores, la nacionalización de la tierra y de la industria, comidas gratuitas en los colegios, la jornada de ocho horas, el fin de los privilegios de la Iglesia anglicana y el autogobierno (home rule) de Escocia. Su vehemencia lo llevó a ser amonestado varias veces en el Parlamento, y en 1887 pasó varias semanas en la cárcel por oponer resistencia a una carga policial durante una manifestación. En

2 En los casos en los que ha sido posible consultar una obra en español, la cita se aporta en este idioma. En los que no ha sido así, la cita se aporta en el inglés original.

3 Mi fuente principal para la vida de Cunninghame Graham es Anne Taylor, The People's Laird: A Life of Robert Bontine Cunninghame Graham. Easingwold: Tobias Press, 2005. Existe una abundante bibliografía acerca de este personaje, tanto en español como en inglés, aunque poca de reciente publicación. De los trabajos anteriores a 1980 hace un buen resumen John Walker, "Cunninghame Graham: una nueva perspectiva crítica”, en Revista canadiense de estudios hispánicos, vol. $4, \mathrm{n}^{\circ} 2$ (1980), pp. 218-224. Un buen trabajo, aunque muy centrado en el Reino Unido, es Cedric Watts y Laurence Davies, Cunninghame Graham: A Critical Biography. Cambridge: Cambridge University Press, 1979. 
1892, convencido de que el Partido Liberal no defendía los derechos de la clase obrera con la suficiente determinación, Graham abandonó su escaño y colaboró con Keir Hardie en la fundación del Independent Labour Party, semilla del actual Partido Laborista. Con el tiempo, Cunninghame Graham también sería una de las principales figuras del independentismo escocés, fundando y presidiendo el Partido Nacionalista Escocés.

En paralelo a sus actividades políticas, Graham desarrolló una importante faceta literaria. A lo largo de su vida publicó unos doscientos relatos breves y una decena de libros de historia. El eje fundamental de su obra de ficción fue dar vida a las impresiones que había obtenido en sus viajes por el mundo, combinando elementos de la narrativa breve, la literatura costumbrista y los libros de viajes 4 . En este sentido, las dos regiones que aparecen con mayor frecuencia en estos relatos son Hispanoamérica (en particular Argentina) y el norte de África (en particular Marruecos) $)^{5}$. La obra histórica, por su parte, se centró fundamentalmente en la conquista y colonización de Hispanoamérica por parte de los españoles o de sus descendientes criollos. Cunninghame Graham escribió tanto biografías de Hernando de Soto, Pedro de Valdivia y Bernal Díaz del Castillo como un estudio de las misiones jesuitas en Paraguay.

De gran importancia en la vida y obra de Cunninghame Graham fue su esposa, cuya vida resulta tan aventurera y pintoresca como la suya. Nacida Caroline Horsfall en una aldea de la provincia inglesa de Yorkshire, huyó de casa a los dieciséis años y llegó hasta París, donde estuvo varios años ganándose la vida como actriz. Allí conoció a Cunninghame Graham en una de las ocasiones en que éste se encontraba de paso por la capital francesa. Decididos a contraer matrimonio, la pareja urdió una compleja ficción para esconder el hecho de que Graham se había casado con alguien de un origen social muy inferior al suyo. Caroline dijo llamarse Gabrielle de la Balmondière y ser hija de padre francés y madre espańola, nacida en Chile pero educada en París tras haber quedado huérfana a los once ańos. Esa fue la historia que conocieron todos los que a partir de entonces tuvieron contacto con ella, y no fue hasta varias décadas después de su muerte cuando se descubrió su verdadera identidad ${ }^{6}$. En todo caso, quien había sido

4 Sobre la base autobiográfica de su obra literaria, ver Taylor, People’s Laird, pp. 101-2.

5 Sus textos sobre Marruecos han sido analizados como parte de la literatura orientalista británica en Andrew C. Long, Reading Arabia: British Orientalism in the Age of Mass Publication. Syracuse: Syracuse University Press, 2014. Sus textos acerca de Argentina están recopilados en edición crítica en The South American Sketches of R. B. Cunninghame Graham. Norman, University of Oklahoma Press, 1978. El contexto de las "novelas geográficas" británicas de principios del siglo XX, fundamental para entender la obra de Cunninghame Graham, está explicado por Richard Maxwell y Katie Trumpener, "The Romance of the Outlands: The fin-de-siècle Adventure Story between History and Geography", en The Yearbook of English Studies, vol. 41, no 2 (2011), pp. 106-124.

6 El descubrimiento de la verdadera identidad de Gabrielle, en Jean Cunninghame Graham: Gaucho Laird. The Life of R. B. Cunninghame Graham. Glasgow: The Long Riders' Guild, 2004. El 
Caroline Horsfall tuvo durante el resto de su vida un importante desempeño político, formando parte de organizaciones feministas y participando en algunos de los círculos socialistas de su marido. También desarrolló una faceta literaria, firmando traducciones, poemas, relatos, ensayos y una extensa biografía de Santa Teresa. Su interés por España le hizo publicar sus trabajos como "Gabriela" (en vez de la primera versión que había utilizado de su nombre falso, "Gabrielle"), nombre que se utilizará también en este trabajo.

\section{MEDIACIÓN LITERARIA}

Cunninghame Graham escribió en una ocasión que "me crié entre españoles, tengo sangre española, soy (creo) cristiano viejo por los cuatro costados, y durante toda mi vida he profesado siempre amor y cariño hacia Espańa y los españoles". Siendo todo esto cierto, también lo es que los numerosísimos viajes a España que realizó a lo largo de su vida parecen haberse debido más a la condición de nuestro país como lugar de paso hacia Marruecos, a la localización de archivos y bibliografía (tanto para sus investigaciones sobre la vida de los conquistadores como para las de su mujer sobre el misticismo español), o a varios negocios infructuosos que trató de poner en marcha para reflotar la economía familiar, que a un verdadero interés por la España de su época. ${ }^{8}$

Esta presencia frecuente pero relativamente tangencial de España en la biografía de Cunninghame Graham tiene su correlato en su obra escrita. Ésta no suele estar centrada en España de forma directa, prefiriendo, como se ha mencionado, espacios árabes o hispanoamericanos. A pesar de esto, sin embargo, diversos factores hacen que su obra contenga numerosas consideraciones acerca de España, y que podamos considerarla como una importante fuente de información e interpretación acerca de la historia y la cultura españolas para los lectores anglosajones de la época.

El caso paradigmático es la presencia de España en su obra histórica. Si bien sus libros sobre las distintas figuras y facetas de la Conquista transcurren, narrativamente, en tierras americanas, tanto el origen de sus biografiados como el contexto de sus empresas lo llevan a dedicar un espacio considerable a las caracte-

tema también se aborda en Jad Adams, "Gabriela Cunninghame Graham: Deception and Achievement in the 1890s", en English Literature in Transition, vol. 50, no 3 (2007), pp. 251-268. El engaño de los Cunninghame Graham ha dado pie a una novela: Clare Clark, Beautiful Lies. Londres: Harvill Secker, 2012.

7 Según un texto citado en El Motín, 11 de mayo de 1911.

8 Taylor señala que Cunninghame Graham recurrió con frecuencia a los archivos de Simancas para sus investigaciones acerca de la vida de los conquistadores. La primera de estas visitas habría sido en 1878. A lo largo de su vida Cunninghame Graham también recurriría a las casas de sus amigos espańoles como sitios a los que escaparse de la vida en Reino Unido, como sucedió durante los años 20 con la casa de su amigo el Duque de Frías en la Sierra de Guadarrama; Taylor, Peoplés Laird, pp. 84, 322. 
rísticas del imperio español y del país que lo forjó. Esto resultaba relevante en un contexto en el que la mayoría de británicos tenía una idea de España basada más en la del siglo XVI que en la del presente, dada la importancia que se otorgaba al contraste y conflicto entre ambos países en la historiografía whig. Esto se unía a la creencia, ampliamente extendida en la Europa de finales del siglo XIX, de que cada pueblo / nación tenía una serie de características que permanecían básicamente inalteradas a lo largo de los siglos. Dado todo esto, lo que Cunninghame Graham escribiera acerca del imperio español de los siglos XVI y XVII actuaba sobre la imagen que sus compatriotas tenían tanto de la España del pasado como de la del presente.

Resulta muy significativo, por tanto, que Cunninghame Graham elaborase una visión de la Conquista altamente ambivalente, una en la que las críticas desde el punto de vista humanitario se unían a un importante relativismo histórico. En su biografía de Bernal Díaz del Castillo, por ejemplo, encontramos el siguiente pasaje:

Arrogancia, crueldad y orgullo de raza, sed de oro y una fe ciega en su religión, unida a una indiferencia absoluta con respecto a los demás hombres, constituyeron los defectos principales de todos los conquistadores españoles; pero en su mayor parte estas faltas son inherentes a la humana naturaleza, en especial a aquellos que se encuentran colocados en una posición de predominio [...] ¿Quién osaría hoy en Inglaterra, Francia o España o en cualquier otro país, emitir alguna crítica de su comportamiento? [...] Ellos se creían los instrumentos de Dios, exactamente igual que nosotros nos creemos los instrumentos del progreso. ${ }^{9}$

Efectivamente, la interpretación que hizo Cunninghame Graham de la Conquista estuvo en gran medida condicionada por su posición crítica hacia el imperialismo europeo del siglo XIX. Central al mismo era la idea (resumida en el conocido poema de Rudyard Kipling, “The White Man's Burden”, de 1899) de que el imperialismo moderno era una empresa altruista que buscaba mejorar las condiciones de vida de pueblos incapaces de autogobierno, y extender entre ellos los logros del progreso. Cunninghame Graham rechazaba esta visión autocomplaciente, considerando que el imperialismo de su época se movía por las mismas motivaciones egoístas que el del siglo XVI, y que en muchos aspectos era peor que éste. Así, sus consideraciones negativas acerca de la acción colonial de los españoles se enmarcan siempre en una crítica más amplia a los supuestos culturales

9 Robert B. Cunninghame Graham, Bernal Díaz del Castillo: Historiador de la conquista. Sevilla: Espuela de Plata, 2010, p. 23. 
que subyacían al imperialismo europeo en América, en África y en Asia. Veamos algunos ejemplos:

El progreso y la civilización mal aplicados son las principales maldiciones que los europeos han llevado hasta los rincones más remotos del orbe, matando, esclavizando y conquistando en su nombre. ${ }^{10}$

A estilo de todos los capitanes europeos, tanto en la América de aquellos tiempos como en el África de épocas posteriores, lo primero que hacían [los conquistadores españoles] era proclamar que los hombres que habían estado defendiendo su propio país eran traidores y rebeldes a su Rey. [...] Una vez asegurado esto, estuvieron en iguales condiciones -como los franceses, italianos y nosotros mismos en la actualidad, en África- de fingirse funcionarios que actúan legalmente. ${ }^{11}$

Lo que fue África en los últimos veinte años, fue la América Hispana hace trescientos; la diferencia es que, mientras la moderna aventura en África es observada por todos y trata con pueblos completamente incivilizados en su mayoría, la conquista de América del Sur tuvo el encanto de lo novedoso e hizo conocer a los conquistadores dos pueblos casi tan avanzados como ellos. ${ }^{12}$

Dejando de lado los hechos de las islas de las Indias Occidentales, que nadie puede disculpar ni aun mitigar, [las] otras hazañas [de los españoles] en el continente del Nuevo Mundo, ciertamente no son más vituperables que aquellas de los franceses, ingleses u holandeses en similares circunstancias. ${ }^{13}$

Como se puede ver, para Graham no se podía hacer una apreciación del imperio español del pasado sin hacerla también de los imperios británico, francés, belga, etc. de su tiempo. En realidad, esto no era algo que hubiese inventado él: Graham era consciente de que una de las causas de la autocomplacencia británica respecto a su labor imperialista era precisamente el análisis peyorativo que del imperio español habían realizado historiadores como William H. Prescott. En

10 Cunninghame Graham, Bernal..., p. 139.

11 Cunninghame Graham, Bernal..., pp. 164-65

12 Robert B. Cunninghame Graham, La Arcadia perdida. Una historia de las misiones jesuiticas. Buenos Aires: Emecé, 2000, p. 27.

13 R. B. Cunninghame Graham, Los caballos de la conquista. Sevilla: Espuela de Plata, p. 27. 
otras palabras, Cunninghame Graham sabía que escribir acerca de la Conquista en Reino Unido era hacerlo en un contexto historiográfico que había sido profundamente hostil al imperio español, y que había derivado de aquella hostilidad toda una serie de tesis acerca de la superioridad de la colonización británica sobre la espańola, y por ende de la superioridad de la "raza anglosajona" sobre la "raza latina”. Cunninghame Graham daba la vuelta a estas tesis, respetando el marco conceptual de comparar imperios, pero derivando conclusiones opuestas a las de Prescott. No negaba que las razas, entendidas en un sentido laxo y eminentemente cultural, existiesen (en este sentido, seguía siendo un hombre de su época); pero sí que tuvieran las características que se les habían adscrito. Según él, "el error de Prescott es contemplar estas cosas desde el punto de vista anglosajón, y haberse formado una idea equivocada de la raza y características latinas"14.

De este modo, la revisión llevada a cabo por Cunninghame Graham de las tesis de Prescott era también una manera de minar las bases sobre las que se asentaba el pensamiento colonial británico. Su libro sobre las misiones jesuitas de Paraguay, por ejemplo, buscaba contrarrestar el "artículo de fe anglosajona que las colonias hispanas estuvieron mal administradas y todos los conquistadores españoles fueron carniceros sanguinarios" ${ }^{15}$. Y el contraste es más explícito en su biografía de Bernal:

Si fue para bien, o para mal, sólo el tiempo habría de decirlo, pero los españoles no observaron nunca la diferencia de raza en sus relaciones con los indios, contrariamente a los anglosajones, y, en consecuencia, cuando la furia de la conquista se consumó, el trato que les dieron, obligados en su mayor parte por la necesidad, fue morigerado. ${ }^{16}$

Este pasaje nos permite descubrir una capa adicional de complejidad en la ambivalencia de Cunninghame Graham hacia el imperio español. Graham no fue un antiimperialista sin matices: por muy crítico que se muestre a veces en sus libros con las acciones de Cortés o Valdivia, resulta evidente que se identifica más con los europeos que viajan a América que con los habitantes de la América precolombina ${ }^{17}$. También esto era una cuestión de contexto: Graham escribió y pensó en una época en la que existía una fuerte corriente crítica en Reino Unido

14 Cunninghame Graham, Bernal..., p. 115.

15 Cunninghame Graham, La Arcadia perdida, p. 18.

16 Cunninghame Graham, Bernal..., p. 80.

17 Esto, que es cierto de sus textos, también parece haberlo sido de su vida. Cunninghame Graham intentó durante varios años organizar una compañía que explotara económicamente los recursos de una zona del sur de Marruecos, con el beneplácito de los gobiernos español y francés; Taylor, People's Laird, pp. 281-284. 
hacia su imperio, pero no por eso dejaba de creer en que la acción de las potencias europeas sobre los pueblos bajo su dominio podía ser benéfica. Esta corriente, que incluía a importantes figuras de la izquierda como George Bernard Shaw, Ramsay MacDonald y J. A. Hobson, comprendía las faltas morales del imperio británico, pero no por eso creía en el mal intrínseco de todos los imperios ${ }^{18}$. Es más, aceptaba que el imperialismo era un hecho de las relaciones internacionales, y que lo que debía hacerse era darle la forma más progresista y menos hipócrita posible. Cunninghame Graham adoptó también esta suerte de relativismo; de hecho, G. K. Chesterton dejó constancia de una intervención del escocés en una mesa redonda acerca del imperialismo en la que "[fue] justo con los imperios en cuanto imperios"19.

Así pues, Cunninghame Graham podía incluir comentarios en sus libros de historia que demostraban su aprecio por las culturas precolombinas, admirando su "sentido común y habilidad" o declarando que "es imposible dejar de sentir la suerte de los quebrantados mexicanos que luchaban desesperadamente en defensa de sus propios hogares" 20 . Pero no tiene ningún empacho en referirse a las civilizaciones precolombinas como "salvajes", y en admirar la buena labor que, según él, habrían realizado los españoles en América: "en América y sobre todo en el Paraguay, la Orden hizo mucho bien [...] los jesuitas hicieron felices a los indios" 21 . En cuanto a los conquistadores, es frecuente que Graham los compare con gente con la que ha congeniado a lo largo de sus viajes por Hispanoamérica: "Me complace pensar que [...] he tenido algunas oportunidades para comprender a un hombre como Bernal Díaz"22. Y es que la narración de sus obras históricas está focalizada siempre a través de los ojos de los conquistadores, a pesar de que en ocasiones desee distanciarse de los mismos mediante comentarios y acotaciones. Su obra es, así, un curioso ejemplo de lo que él mismo comenta acerca de su experiencia leyendo a Bernal:

A medida que se lee su relato, se olvida uno que cómo todos los españoles, Cortés, Bernal Díaz y Sandoval no eran más que una banda de piratas; debido al arte inconsciente con que narra la

18 Bernard Porter, Critics of Empire: British Radicals and the Imperial Challenge. Londres: I.B. Tauris, 2008. El impacto de esta corriente en los conceptos de principios del siglo XX de la Hispanidad, en David Jiménez Torres, Ramiro de Maeztu and England: Imaginaries, Realities and Repercussions of a Cultural Encounter. Woodbrige: Tamesis, 2016, pp. 148-158.

19 G. K. Chesterton, Autobiografía. Barcelona: Acantilado, 2003, p. 310.

20 Cunninghame Graham, Bernal..., pp. 112, 195.

21 Cunninghame Graham, La Arcadia perdida, p. 17.

22 Cunninghame Graham, Bernal..., p. 26. 
historia, uno llega a interesarse por el destino de los expedicionarios, aún contrariando a su propia razón. ${ }^{23}$

Tanto esta identificación narrativa como la relativización del imperialismo español colocan a Graham en posición de admirar ciertos aspectos de los conquistadores. De Bernal, por ejemplo, alaba la "sinceridad" con que escribe acerca de los motivos religiosos y pecuniarios de sus acciones, concluyendo que "esos tiempos eran más rudos que los actuales [...] pero menos hipócritas" ${ }^{24}$. Y de Cortés es capaz de alabar su pericia y valentía:

La maravillosa expedición había concluido, quedando, en opinión de muchos peritos en asuntos militares, como una de las más extraordinarias que pueden citarse en los anales de la humanidad. Cortés y sus hombres estaban realmente fundidos en el molde de los héroes. Cuerpos de hierro, con almas de acero, a prueba de toda clase de peligros y privaciones. ${ }^{25}$

Lo que nos interesa aquí es que Graham explica a menudo esas cualidades -valentía, sinceridad, nobleza- al lector como si fueran intrínsecas al carácter español. Alaba el hecho de que "no puede decirse jamás que los españoles se hayan retirado cuando se trató de luchar", y cree que en la obra de Bernal se pueden ver los "sentimientos de justicia y orgullo tan propios de los corazones hispanos" 26 . También es frecuente que regionalice estas cualidades, como cuando dice que Bernal "parece haber sido un buen castellano de su época en cuanto se refiere al honor"; y que su obra "demuestra la sobriedad del carácter castellano, tan parco y ordenado en todas las cosas y enemigo acérrimo de todos los extremos" ${ }^{27}$.

Vemos así que Cunninghame Graham planteó una visión positiva del carácter español, precisamente derivada de la época en que se había forjado una imagen negativa del mismo en Reino Unido. Al hacer esto, sin embargo, también insertaba a España en la ecuación modernidad/antimodernidad que tan importante resultaba para los proyectos políticos en los que militaba. En su obra histórica, por ejemplo, refuerza las descripciones esencialistas del carácter español que ya hemos visto con unas descripciones de la Castilla rural perfectamente homologables a las

23 Cunninghame Graham, Bernal..., p. 192.

24 Cunninghame Graham, Bernal..., pp. 21, 166.

25 Cunninghame Graham, Los caballos de la conquista, p. 53. No resulta menor el hecho de que fueran los conquistadores espańoles quienes llevaron los caballos al Nuevo Mundo, puesto que la equitación fue una de las grandes pasiones de Graham. El libro del que se extrae esta cita alaba, precisamente, la relación que tenían los españoles con sus caballos.

26 Cunninghame Graham, Bernal..., pp. 100, 21-3.

27 Cunninghame Graham, Bernal..., pp. 97, 111. 
de sus coetáneos Azorín y Antonio Machado, y que evidencian una estetización de la presunta antimodernidad española ${ }^{28}$.

Este aspecto queda patente también en uno de los pocos relatos de Graham que incluyen a personajes españoles. Se trata de "Victory", cuento recogido en el volumen Thirteen Stories (1900) cuya acción transcurre en una ciudad estadounidense el día en que llegan noticias de la derrota definitiva de la escuadra espańola en la guerra de 1898. Mientras los estadounidenses leen con alegría los periódicos y fantasean acerca de su incipiente hegemonía global, el narrador reflexiona que:

cuando herimos a un hombre y vemos su sangre podemos conocer su naturaleza por la manera en que éste lleva su herida, y los españoles, heridos de muerte, seguían presentando batalla [...] mientras los yanquis chillaban como perros callejeros a la primera ocasión, a pesar de su dinero, de su número y de tener todo a favor. Vino entonces a mi memoria la España de antaño: la de Íñigo López de Mendoza, el Gran Capitán y Cortés (no en el sitio de Méjico, sino en Argel). Y pensé en la larga lucha librada a lo largo de más de setecientos años gracias a la cual los españoles habían salvado a la mitad meridional de Europa de la dominación árabe. Pensé en Gerona, en Zaragoza y principalmente en Cervera, el último de los Quijotes. ${ }^{29}$

En ese mismo instante, el narrador ve entre la muchedumbre a un viejo espanool con "el aire fatalista y de desencanto de una sabiduría mundana entremezclada de ingenuidad que es lo que caracteriza al español de la vieja escuela" ${ }^{30}$. Ante las noticias de la derrota, el viejo se mantiene "tan impasible como un faquir o como un guerrero indio en su puesto de vigilancia" ${ }^{1}$. Posteriormente se levanta y se aleja "entre las densas filas de enemigos vencidos" 32 .

La comparación del viejo español con un faquir y con un guerrero indio indica que los españoles, según la perspectiva de Cunninghame Graham, habían entrado en 1898 en la categoría de pueblos vencidos por la modernidad occidental. El escritor inviste así a la imagen de España de cualidades asociadas con la épica de la antimodernidad: el estoicismo, el valor, el sacrificio, la nobleza en la derrota; todo contrastado narrativamente con la presunta vulgaridad y arrogancia modernas que encarnan los estadounidenses.

28 Descripciones de este tipo en Cunninghame Graham, Bernal..., pp. 29-31.

29 R. B. Cunninghame Graham, Trece historias. Sevilla: Espuela de Plata, 2006, pp. 186-7.

30 Cunninghame Graham, Trece historias, p. 189.

31 Cunninghame Graham, Trece historias, p. 190.

32 Cunninghame Graham, Trece historias, p. 191. 
Esta inserción de España en la antimodernidad bebía también de la fascinación que sintió Cunninghame Graham por el mundo árabe y por su huella en España. El relato breve "Sohail" rememora la dominación musulmana de la Península, añadiendo después:

Trenes, telégrafos y fonógrafos, elecciones y debates en el Parlamento y trajes que son un disfraz acabaron por dar un falso aire europeo al país. Las palmeras, los cactus y los olivos, las tapias, el caminar y los ojos de las mujeres, el paso de los caballos y el fatalismo que envuelve todas las cosas, revelan fácilmente el engaño, pues el imperio árabe, aun yéndose, se quedó. [...] Todo el territorio que se extiende desde las delgadas montañas del norte hasta las cálidas marismas del Guadalquivir (desde Sevilla a Sanlúcar) pertenece a África. ${ }^{33}$

Como sucede con su visión del imperio español, las descripciones de Cunninghame Graham de la antimodernidad española guardan relación con su pensamiento político. Una parte importante de su ideario era, efectivamente, la evocación de un medievo que serviría de modelo para un socialismo anti-industrial. Un medievo que, si bien había desaparecido de Europa occidental, aún podría encontrarse en otros países y otras tradiciones: en 1889, tras un viaje a Marruecos escribió que "I have seen what England was like in the Middle Ages (...) Is not a country where each man cultivates his own little plot, sits in his own little shop, works at his own loom, wields his own hammer at his own forge, nearer to Socialism than England?" ${ }^{4}$. Del mismo modo, en opinión de Cunninghame Graham las misiones jesuitas en Paraguay habían estado organizadas en una suerte de "semicomunismo", mientras que la expulsión de los jesuitas sólo habría traído "el comercialismo" ${ }^{35}$. El resultado: "la vida sencilla y ceremoniosa" de las misiones se deshizo "al primer contacto con la vivificadora competencia: esa competencia que ha vuelto gris al mundo entero, reduciéndolo todo y a todos al más bajo denominador común" ${ }^{36}$. De esta forma, vemos que las descripciones positivas que Graham hace del pasado y el presente españoles forman parte de un proyecto político derivado del socialismo estetizante de su época. Si Ruskin y Morris hallaron su Arcadia preindustrial en la Edad Media europea, Cunninghame Graham la halló en los mundos árabe e hispano. 
Todo esto nos permite abordar la única obra de Graham que está dedicada exclusivamente a la España contemporánea: Aurora la Cujiñi: A Realistic Sketch in Seville (1898). Se trata de un relato breve acerca de una tarde en Sevilla, en la que una corrida de toros es seguida de un espectáculo de flamenco en una taberna. El vocabulario empleado por el narrador a lo largo de toda la obra transmite exotismo y deshumanización: la doble herencia de España -árabe y romana- hace que sobre Sevilla cuelgue un "mixed air of sensuousness and blood" ${ }^{37}$. En cuanto a los sevillanos presentes en la taberna, en opinión del narrador, son "almost medieval", representantes de "the not too anthropomorphic-looking scum which swarms in Seville and in every Southern Spanish town"38. La descripción de las mujeres sigue una tónica parecida, asociándolas con las tribus africanas o directamente con animales:

The women suddenly begin to clap their hands in a strange rhythm, monotonous at first, but which at length, like the beating of a tom-tom, makes the blood boil [...] Then one breaks out into a harsh wild song, the interval so strange, the time so wavering, and so mixed up the rhythm, that at first it scarcely seems more pleasing than the howling of a wolf. ${ }^{39}$

La bailarina que encandila al narrador tiene, de nuevo, un toque animal: "she had a look [...] as of a mare about to kick" ${ }^{40}$. El animalismo se mezcla con el erotismo: su arabesco final dibuja "a very statue of impudicity", ante la cual los hombres se quedan boquiabiertos "like satyrs" ${ }^{41}$. Y la desaparición final de la bailarina la acerca al mundo de lo sobrenatural: "perhaps at witches' Sabbaths she still dances, or perhaps in that strange Limbo where the souls of gypsies and donkeys dree their weird"42.

Aurora la Cujiñi se enmarca cómodamente, por tanto, en el género romántico de representaciones de España. Las comparaciones con el mundo animal, con civilizaciones no-europeas y con lo sobrenatural permiten una identificación de lo español con una alteridad antimoderna. De nuevo, esto encaja con un ideario político y una sensibilidad estética que reivindican todo aquello que vaya en con-

37 R. B. Cunninghame Graham, Aurora la Cujiñi: A Realistic Sketch in Seville. Londres: Leonard Smithers, 1898, p. 10.

38 Cunninghame Graham, Aurora... p. 17-18.

39 Cunninghame Graham, Aurora... p. 19.

40 Cunninghame Graham, Aurora... p. 20

41 Cunninghame Graham, Aurora... p. 22. El lenguaje erótico utilizado para describir el baile de la folclórica dificultó el proceso de encontrar a un editor para la obra; Taylor, Peoplés Laird, p. 276.

42 Cunninghame Graham, Aurora... p. 22. 
tra de la modernidad industrial. Sin embargo, es de notar la conciencia que tiene el narrador del papel que desempeñan los propios viajeros europeos en la creación de una imagen romántica del país. En la corrida de toros que abre la obra, el narrador declara que "the British tourists, after condemning Spanish barbarism, had taken boxes to a man, and come away delighted with the picturesqueness of the show" ${ }^{43}$. Igualmente, el erotismo de la bailarina queda reforzado mediante las reacciones escandalizadas de los turistas: "in the box where sat the foreign ladies, one has turned pale and rests her head upon the other's shoulder, who holds her round the waist" 4 .

La inclusión de las reacciones de los turistas muestra que el narrador es consciente de que ya no es un viajero solitario en territorio desconocido, sino más bien un turista entre muchos otros. El cambio viene marcado por la realidad histórica: en los años en los que escribe Cunninghame Graham España ya recibe un número considerable de viajeros extranjeros..$^{45}$ Esto hace que se diluya el valor testimonial que puede aportar el autor en base a su sola condición de extranjero, y que su narrador deba encontrar formas de destacar su perspectiva frente a la de un turista al uso. Así, el narrador trata despectivamente a sus compatriotas, acusados (como ya hemos visto) de mojigatería o de hipocresía, y hace esfuerzos por mostrar una gran familiaridad con la cultura española, haciendo referencia a Lope de Vega, Calderón de la Barca, Echegaray y Moratín. De esta forma, podemos considerar que el opúsculo de Graham representa un momento de transición en las representaciones de España realizadas por extranjeros. Nos muestra que en los albores del siglo XX la alteridad española mantenía su atractivo para ciudadanos de países más desarrollados, en parte debido a su utilidad para algunos proyectos políticos y estéticos; pero también comenzaba a ajustarse a un público lector cada vez más viajero.

Antes de cerrar esta sección, hay que destacar que Gabriela Cunninghame Graham también ejerció una importante labor de mediación entre España y Reino Unido a través de textos literarios. Además de su biografía de Santa Teresa, tradujo Don Juan Tenorio y Noche oscura del alma y publicó una colección de cuentos ambientados en España -titulada The Christ of Toro- y varios ensayos y artículos sobre la España contemporánea. ${ }^{46}$ Estas obras muestran una actitud pa-

43 Cunninghame Graham, Aurora... p. 11.

44 Cunninghame Graham, Aurora... p. 22.

45 Un análisis de las nuevas empresas que buscaban fomentar el viaje entre ambos países a principios del siglo XX, en Kirsty Hooper, Mondariz-Vigo-Santiago: A Brief History of Galicia's Edwardian Tourist Boom. Mondariz: Fundación Mondariz Balneario, 2013.

46 Las obras se comentan en Taylor, People's Laird, p. 288; y en Adams, "Gabriela Cunninghame Graham...", p. 257. Las ediciones de los libros son: Gabriela Cunninghame Graham, The Christ of Toro. Londres: Eveleigh Nash, 1908; y St John of the Cross, The Dark Night of the Soul. Done into English by Gabriela Cunninghame Graham. Londres: J. M. Watkins, 1922. La traducción de Don 
recida a la de su marido, esto es, la reivindicación positiva de la antimodernidad española. En un ensayo declaraba que, en lo que a España se refería, "we find the natural manners and customs unchanged since the Middle Ages, virtually unaltered from what they were when the Moors and Spaniards lived side by side together in the heart of the Peninsula" ${ }^{47}$. Del mismo modo que su marido había mostrado su desacuerdo con Prescott, Gabriela mostró su desacuerdo con Richard Ford, explicando que en España había "more to respect, to love, to admire, in the proud, self-respecting dignity, the simple sober habits, the native good manners and kindness which are the characteristics of all classes of the nation". En cuanto a su obra principal, la biografía de Santa Teresa, fue un trabajo de una importante erudición que buscaba contextualizar las visiones de la santa en una fenomenología más amplia del misticismo ${ }^{48}$. Sin embargo, y a pesar de que tanto Maeztu como Pérez de Ayala le dedicaron elogios en la prensa, el libro nunca alcanzó la repercusión en España que los Graham habrían querido ${ }^{49}$. Tampoco gozaron de éxito ni sus relatos ni sus traducciones de Zorrilla y de San Juan de la Cruz. Así pues, si bien la labor de Gabriela como productora o transmisora de textos acerca de la cultura española está, cuantitativamente, a la par que la de su marido, no se puede decir lo mismo en lo que se refiere a su repercusión.

\section{MEDIACIÓN SOCIAL}

La labor del mediador no se limita a la producción o transmisión de textos. A menudo, los mediadores desempeñan también una función de nexo social, actuando como punto de contacto entre individuos y grupos de dos naciones distintas que no se habrían conocido de no ser por su intervención. Con el tiempo, esta labor puede forjar verdaderas redes de intercambio de conocimientos (sean textos, ideas, corrientes artísticas o de pensamiento), o sencillamente funcionar como base experiencial para la imagen que se tiene de los habitantes de otro país.

Cunninghame Graham fue un buen ejemplo de todo esto. Su carácter sociable, su condición de primogénito de una familia aristocrática y su interés por -y talento para- la política y la literatura lo convirtieron, desde una edad relativamente temprana, en una persona excelentemente conectada. En el mundo de la política gozaba de relaciones particularmente estrechas con los círculos socialistas y anarquistas de Londres, siendo un participante habitual tanto en las tertulias de

Juan no se llegó a publicar, sino que formó parte de una adaptación teatral.

47 Cit. en Taylor, p. 104.

48 Gabriela Cunninghame Graham, Santa Teresa, Being Some Accounts of Her Life and Times Together with Some Pages from the History of the Last Great Reform in the Religious Orders. Londres: Eveleigh Nash, 1894. El texto no se traduciría al español hasta 1927, en las Publicaciones de la Revista de Occidente.

49 Los elogios de Maeztu y Pérez de Ayala, en La Correspondencia de España, 15 de mayo de 1905, y en El Imparcial, 16 de octubre de 1907. 
los socialdemócratas liderados por H. M. Hyndman como en las de los marxistas reunidos alrededor de Friedrich Engels ${ }^{50}$. También era un estrecho colaborador de las grandes figuras del movimiento laborista, ya fuesen políticos como Keir Hardie y Ramsay MacDonald o líderes sindicales como Tom Mann. Sus contactos se extendían también al mundo de las artes plásticas, al de los negocios, al de la diplomacia y al de la literatura, en el que tuvo trato con las principales figuras de su tiempo: Oscar Wilde, G. K. Chesterton, George Bernard Shaw, Ford Madox Ford, John Galsworthy o el ya mencionado Joseph Conrad. Este trato fue en algunos casos tan asiduo como fructífero: algunas de las anécdotas que contó a Conrad acerca de sus experiencias en Sudamérica inspiraron la trama de la novela Nostromo, y también es posible que le aportara información acerca del anarquismo londinense durante la redacción de The Secret Agent ${ }^{51}$.

Por desgracia, aún queda por hacer una reconstrucción detallada de la génesis y la extensión de los contactos de Cunninghame Graham en España. Sin embargo, las referencias a su persona tanto en la prensa espańola de la época como en las memorias de sus contemporáneos nos aportan una idea aproximada de la amplitud de dicha red de contactos. Graham parece haber tenido trato con figuras que luego serían adscritas a las generaciones del 98 y del 14, como Ramiro de Maeztu y su hermana María, Pío Baroja, Ignacio Zuloaga, José Ortega y Gasset o Ramón Pérez de Ayala. Este último, por ejemplo, dejó escrito que se habían conocido cuando él (Ayala) era todavía un estudiante; y en un artículo de 1911 hablaba de una cena en Madrid en honor a Cunninghame Graham organizada por el dramaturgo Gregorio Martínez Sierra ${ }^{52}$. Debido a sus inclinaciones políticas, Graham también estuvo en contacto con sectores socialistas y anarquistas españoles, algo que lo llevó a participar activamente en las protestas por la ejecución de Francisco Ferrer en 1909. Precisamente esto le condujo a una polémica con Azorín, en el curso de la cual escribió que "día vendrá en que la España que yo amo, la joven, la regenerada, la liberal, se coloque en su debido puesto en los consejos de Europa" ${ }^{\prime 3}$. Dado este nivel de contactos no sorprende que durante la Primera Guerra Mundial los servicios de propaganda británicos pensaran en

50 Taylor, People's Laird, p. 211.

51 Cedric Watts, "Context for The Secret Agent, with a Letter from R. B. Cunninghame Graham", en The Conradian, vol. 36, no 1 (2011), pp. 80-88. Las cartas de Conrad a Graham fueron recopiladas en C. T. Watts (ed.), Joseph Conrad's Letters to R. B. Cunninghame Graham. Cambridge: Cambridge University Press, 1969.

52 Heraldo de Madrid, 5 de julio de 1911. El recuerdo de haber conocido a Cunninghame Graham, que por desgracia es bastante parco en detalles, en Ramón Pérez de Ayala, Amistades y recuerdos. Barcelona; Aedos, 1961, p. 120.

53 Extractos de la polémica entre Azorín y Graham, a propósito de la ejecución de Francisco Ferrer, recogidos en El Motín, 11 de mayo de 1911. También parece ser que Graham escribió en ocasiones acerca de España para el periódico Labour Elector, destacando la dureza empleada por las fuerzas de seguridad contra socialistas y anarquistas; Taylor, People's Laird, p. 210. 
él para promocionar en España la causa aliada, algo que los aliadófilos españoles celebraron ${ }^{54}$.

Es fácil ver, por tanto, que Cunninghame Graham se encontraba en una situación ideal para ejercer de nexo social entre sus contactos británicos y españoles. Un ejemplo de cómo funcionó esto en la práctica es el caso de uno de sus amigos pintores, William Rothenstein. En 1894 Cunninghame Graham convenció a Rothenstein para que hiciesen un viaje a Marruecos y España. A su paso por Sevilla, Graham le presentó a Ignacio Zuloaga, lo que condujo a Rothenstein a realizar un retrato del pintor vasco que se acabaría exponiendo meses después en el New English Art Club. Rothenstein también conoció las obras de los clásicos españoles y la interpretación que de ellos hacían los pintores contemporáneos, lo que le condujo a escribir la primera monografía en inglés sobre Goya ${ }^{55}$. A su vez, Rothenstein animó a su cuñado, el pintor irlandés William Orpen, a descubrir la tradición pictórica española, lo que influiría fuertemente en las obras que Orpen realizó en su madurez ${ }^{56}$.

Donde resulta más visible la función de nexo social desempeñada por Cunninghame Graham es en los casos de intelectuales españoles que viajaron a Londres durante estos años. En este sentido, resulta paradigmática su relación con Maeztu, quien se convirtió en 1905 en el primer corresponsal de la prensa española en la capital británica. Las crónicas londinenses de Maeztu mencionan a Cunninghame Graham (a quien se refiere como "mi amigo") con cierta frecuencia, y dan fe de que sus consejos con respecto a las figuras y los círculos más interesantes de la capital tuvieron un profundo impacto ${ }^{57}$. Le presentó, por ejemplo, a George Bernard Shaw, lo cual contribuiría a la fuerte atracción de Maeztu por el socialismo fabiano y su concepto de la figura del intelectual; así, en una charla de 1910 en el Ateneo de Madrid, Maeztu propondría a Shaw como el modelo a seguir por parte de la intelectualidad española ${ }^{58}$. También es posible que Graham fuese quien le presentara a Alfred Richard Orage, seguidor asimismo de William Morris y editor del influyente semanario The New Age. La entrada de Maeztu en esta revista influiría decisivamente en su aproximación al tradicionalismo ${ }^{59}$.

54 La Correspondencia de España, 30 de octubre de 1916.

55 William Rothenstein, Goya. Londres: At the Sign of the Unicorn, 1900.

56 Kenneth McConkey, "Dark Identities: Orpen's Hispanic Repertory", en The British Art Journal, vol. 7, no 3 (2006/7), pp. 62-69.

57 Por ejemplo, en La Correspondencia de España, 16 de abril de 1905 y 21 de enero de 1906.

58 El encuentro, contado por Maeztu, en La Correspondencia de España 30 de abril de 1905. La conferencia en Ramiro de Maeztu, La revolución y los intelectuales. Madrid: Bernardo Rodríguez, 1911.

59 La evolución ideológica de Maeztu, en Pedro Carlos González Cuevas, Maeztu. Biografía de un nacionalista español. Madrid: Marcial Pons, 2003; José Luis Villacañas, Ramiro de Maeztu y el ideal de la burguesia en España. Madrid: Espasa-Calpe, 2000; David Jiménez Torres, Ramiro de Maeztu and England: Imaginaries, Realities and Repercussions of a Cultural Encounter. Woodbridge: 
Otra persona importante con la que Cunninghame Graham parece haber puesto en contacto a sus amigos españoles fue el príncipe anarquista Piotr Kropotkin, amigo personal suyo, a quien tanto Maeztu como Pérez de Ayala dijeron haber conocido durante sus estancias en Londres ${ }^{60}$.

Aparte de presentaciones personales, estaba el acceso que Cunninghame Graham podía dar a los muchos espacios de sociabilidad de la capital británica. Los clubes eran lugares privilegiados donde hacer contactos, y de nuevo el caso de Maeztu es paradigmático: Cunninghame Graham era miembro del Devonshire Club, organización muy vinculada al ala izquierdista del Partido Liberal, y es más que probable que fuera a través de su mediación como Maeztu acabó asistiendo a varias de sus reuniones ${ }^{61}$. Gabriela, por su parte, estaba muy implicada en el Lyceum Club (organizado exclusivamente por mujeres), y fue seguramente a través de ella como Maeztu acabó conociendo, en las instalaciones de aquel club, al escritor peruano Francisco de Rojas ${ }^{62}$. Igualmente, Pío Baroja dejó constancia en sus memorias de que durante sus estancias en Londres en 1905 y 1906 (las que servirían de inspiración para su novela de 1908, La ciudad de la niebla), Graham lo solía llevar a comer; en el curso de estas comidas le presentó a J. M. Barrie -autor de Peter Pan-, a Martin Hume -historiador especializado en España-, y a "otros escritores" cuyos nombres no especifica ${ }^{63}$.

Como vemos en el caso de Baroja, la importancia que podía tener esta función de mediación social no estribaba necesariamente en la influencia que ejerciera un contacto sobre otro, sino que podía restringirse al mero acto de presentar a un escritor español a extranjeros cuya conversación acerca de literatura, historia o política le ayudaran a formarse una idea acerca de Inglaterra o del "carácter inglés". Precisamente sobre Hume escribe Baroja que "tenía opiniones de inglés", y que sus comentarios acerca de literatura lo convencieron de que el gusto literario en aquel país había olvidado ya a Dickens para centrarse en "las novelas inglesas de señoritas".

La labor de mediación social realizada por Cunninghame Graham fue, además, complementaria a la desempeñada por su mujer. Gabriela no sólo tuvo relación con los amigos españoles de su marido, sino que también tuvo sus propios contactos en nuestro país. Destaca principalmente su amistad con Emilia Pardo Ba-

Tamesis, 2016, cap. 3 .

60 Ramiro de Maeztu, Obra. Madrid: Editora Nacional, 1974, pp. 157 ss.; Ramón Pérez de Ayala, Tributo a Inglaterra. Madrid: Aguilar, 1963.

61 Graham como miembro del Devonshire Club, en Taylor, People's Laird, p. 84. Maeztu como asistente ocasional a las reuniones del mismo, en Pedro Carlos González Cuevas, Maeztu. Biografía de un nacionalista español. Madrid: Marcial Pons, 2003, p. 116.

62 González Cuevas, Maeztu..., p. 117.

63 Pío Baroja, Desde la última vuelta del camino. Final del siglo XIX y principios del XX. Madrid: Caro Raggio, 1982, pp. 325-6. 
zán, a quien Bieder cree que unían una serie de valores e intereses parecidos como "a talent for literary expression, a passion for travel, and financial acumen" ${ }^{64}$. Los estudiosos calculan que ambas mujeres se conocieron en 1889, poco después de que Gabriela empezase a visitar España en el marco de su investigación acerca del misticismo. A partir de entonces, Gabriela hizo mucho por difundir la obra de Pardo Bazán en Reino Unido, pronunciando una charla en Londres en 1890 en la que definía a su amiga como "la más grande escritora de España, acaso de Europa -en Inglaterra no puedo nombrar ninguna que se le acerque" ${ }^{65}$. En 1892 también tradujo al inglés Un destripador de antaño y gestionó su publicación bajo un nuevo título: Minia. Gabriela también informó a Pardo Bazán acerca de los esfuerzos sufragistas de Emmeline Pankhurst y la Women's Franchise League, pidiendo (y obteniendo) el apoyo de su amiga para esta organización ${ }^{66}$.

Por su parte, Pardo Bazán trató de dar a conocer a Gabriela en España, enviando sus trabajos a Clarín y a Juan Valera y movilizando contactos para facilitar su estreno como actriz en los teatros españoles ${ }^{67}$. También la ayudó con algunos negocios y con la investigación del libro sobre Santa Teresa, aportando información acerca de archivos y contactos a los que podía recurrir. Sin embargo, fue precisamente el libro de Santa Teresa el que provocó la ruptura entre las dos amigas. La escasa repercusión que tuvo en España el libro de Gabriela frustró enormemente a ésta, y le hizo sospechar que Pardo Bazán había maniobrado para que la Iglesia condenara el libro, advirtiendo a su marido para que no tuviera trato con ella, lo que daría lugar a una confrontación periodística entre Maeztu y Pardo Bazán ${ }^{68}$. Fuese cual fuese la verdad del asunto, el episodio redujo la capacidad de Gabriela de ejercer como mediadora social entre personalidades españolas y británicas más allá de los contactos que su marido y ella ya tenían. Además, su prematura muerte (en 1906) obligaría a su marido a realizar su labor de mediación social en solitario durante las tres últimas décadas de su vida.

\section{MEDIACIÓN ICÓNICA}

Un aspecto que aparece de forma reiterada en los testimonios acerca de Cunninghame Graham es la fuerte atracción personal que ejercía sobre todos los que lo conocían. Es decir, no resultaba interesante a sus contemporáneos únicamente como escritor y como político, o (siguiendo con los temas desarrollados en este

64 M. Bieder, "Emilia Pardo Bazán and Gabriela Cunninghame Graham: A Literary and Personal Friendship", en Bulletin of Spanish Studies, vol. 89, no 5 (2012), pp. 725-749.

65 Bieder, "Emilia Pardo Bazán and...”, pp. 730, 737.

66 Bieder, "Emilia Pardo Bazán and...", p. 732.

67 Bieder, "Emilia Pardo Bazán and...”, pp. 736, 743.

68 Taylor, Peoplés Laird, p. 243; La Correspondencia de España, 15 de mayo de 1905 y 6 de noviembre de 1906. Maeztu volvió a escribir acerca de Gabriela con ocasión de su muerte, en $L a$ Correspondencia de España, 4 de octubre 1906. 
trabajo) como conocedor de la cultura y la historia hispánicas e intermediario entre individuos de distintos países. Más bien había algo en su misma forma de ser que atraía a quienes lo trataban. En palabras de Chesterton, "Cunninghame Graham logró la hazaña de ser Cunninghame Graham. Como Bernard Shaw señalaba, es un logro tan fantástico que en una novela resultaría increíble" ${ }^{69}$. Y Maeztu declaraba en 1916 que "no he conocido a figura alguna humana que me haya interesado tanto", algo que, según aseguraba, le sucedía también a "los muchos centenares de españoles que personalmente le conocen" $"$.

Esta fascinación resulta comprensible dados el carácter aventurero de Graham, su inagotable predisposición a viajar a lugares poco frecuentados por los europeos del momento (Marruecos, la pampa argentina), su porte aristocrático combinado con su apasionamiento político, etcétera. Lo interesante es que esta fascinación fue racionalizada en numerosas ocasiones como el resultado del contacto de Cunninghame Graham con otros países, y en particular con aquellos de habla hispana. No sólo eso, sino que con el tiempo su propia figura fue homologada a una serie de personajes y de mitos del mundo hispano. Así, en ocasiones se lo describió como un gaucho, como un Quijote, como un conquistador o como un hidalgo del Siglo de Oro. El periodista Frank Harris resumió la opinión de muchos cuando declaró que le recordaba a "some Spanish noble who had followed Cortez [sic]"11. Incluso su propia madre le escribió una vez que "I often think that the spirit of [...] a Spaniard who volunteered to go with Columbus or was a friend of Cervantes must have entered into your body, for you are so unlike a $19^{\text {th }}$ or $20^{\text {th }}$ century man"72. Esta identificación con el mundo hispano llegó hasta el punto de que sus conocidos británicos se referían a él como "Don Roberto", y que muchas cartas a él dirigidas comenzaban con un "Dear amigo"; algo que no dejó de sorprender a sus conocidos españoles ${ }^{73}$. La identificación incluso ha tenido cierta trayectoria en los estudios acerca de su figura: su voz en el prestigioso Oxford Dictionary of National Biography explica que, por apariencia y temperamento, "he resembled a Spanish hidalgo".

Como podemos ver, Cunninghame Graham se convirtió en los círculos británicos que frecuentaba en una suerte de icono de la hispanidad, una encarnación de ciertas características que (se suponía) eran propias de los países hispanohablantes. Vale la pena resaltar que el interesado hacía lo posible por fomentar esta asociación. Él también utilizaba palabras sueltas en español en sus cartas a sus conocidos británicos, y animaba a que se le retratara ataviado con objetos que lo identificaran con el mundo hispano. También, como hemos visto, centró su

69 Chesterton, Autobiografía, p. 307.

70 La Correspondencia de España, 30 de octubre de 1916.

71 Taylor, People's Laird, p. 7.

72 Taylor, People's Laird, p. 285.

73 La Correspondencia de España, 21 de enero de 1906. 
obra histórica en los mismos conquistadores españoles con quienes a menudo se le comparaba, y su obra breve en las experiencias que había tenido en el extranjero, a menudo en países hispanohablantes. La identificación tenía, sin duda, sus beneficios: como ha explicado Anne Taylor, el personaje de "don Roberto" suponía una buena máscara tras la cual esconder aspectos menos brillantes de su vida, como los problemas económicos que heredó de su padre y que supusieron una fuente de frustración y desgaste durante la mayor parte de su vida ${ }^{74}$. Por otro lado, la identificación con el mundo hispano otorgaba a Cunninghame Graham un aura de interés y originalidad homologable al concepto de Pierre Bourdieu de la 'distinción', el mismo que Alison Sinclair ha visto como uno de los mecanismos que suelen animar el interés por países y culturas extranjeros ${ }^{75}$. Al fin y al cabo, la identificación de Cunninghame Graham con países lejanos y exóticos suponía uno de los elementos que lo hacían atractivo para los editores británicos, quienes veían en él, entre otras cosas, un nicho de mercado por explorar ${ }^{76}$. Por si esto fuera poco, también había que mantener el engaño de la identidad de su mujer, para quien una performance de su presunta -bien que difusa- hispanidad era una forma tanto de esconder su verdadero origen como de otorgar una legitimidad añadida a sus obras de temática española. No es casualidad que, si bien durante años alternó los nombres de Gabrielle y Gabriela (recordemos que, según la historia que su marido y ella contaron al mundo, su origen era francoespañol), en el momento de publicar su biografía de Santa Teresa prefirió firmar con la versión española del nombre.

En todo caso, la predisposición de Cunninghame Graham a ser asociado con el mundo hispano no habría surtido efecto si no hubieran existido ya en la sociedad británica una serie de estereotipos culturales relacionados con ese mundo. En este sentido, su dimensión de icono de la hispanidad nos aporta una radiografía de buena parte de las ideas que sobre el mundo hispanohablante tenían los británicos de finales del siglo XIX y principios del XX. De los testimonios se desprende que lo que posibilitaba la identificación eran características relacionadas tanto con su apariencia física (su rostro alargado, su barba de chivo, sus bigotes engolados, su altura y delgadez), como con su temperamento (su fama de intrépido, su vehemencia, su idealismo social y político, su tenacidad, su sentido del honor) y con algunas de sus aficiones (el viaje, la esgrima y la equitación). Algo parecido sucedía en el caso de Gabriela, de quien William Rothenstein recordaba "that fire

74 Taylor, People's Laird, pp. 111, 278.

75 Alison Sinclair, Trafficking Knowledge in early twentieth-century Spain: centres of exchange and cultural imaginaries. Woodbridge: Tamesis, 2009.

76 Algo evidente en las declaraciones que sobre él realizó uno de sus editores, Edward Garnett de la editorial T. Fisher Unwin; Taylor, People's Laird, p. 277. 
burning deep in her eyes that seems to us so fitting in those who have Spanish blood"77.

Si bien, en algunos casos, estamos ante un accidente histórico relacionado con los rasgos físicos que la moda o la tradición pictórica habían asociado con España -la imagen del hidalgo alto y enjuto-, en los demás nos volvemos a encontrar con características propias de la épica de la antimodernidad. La predisposición a la aventura y a viajar a zonas del mundo escasamente industrializadas, junto con la afición por los animales, acercaban a Cunninghame Graham a la esfera de la actividad física y el mundo natural frente a un mundo -el de su entorno británicocada vez más urbano e industrializado. Igualmente, la vehemencia, el idealismo extremo y un concepto escrupuloso del honor lo acercaban a unos códigos de conducta que se entendían como propios de épocas anteriores al desarrollo comercial y burgués, o de países donde éste había sido menor (Charles Duff, por ejemplo, explicaba sus excesos verbales en el Parlamento como el resultado de su "Spanish pride") ${ }^{78}$. También latía bajo todo esto una manera de ejercer la masculinidad que muchos en su época consideraban como diametralmente opuesta a la presunta feminización efectuada por la modernidad industrial, con su separación del hombre de actividades viriles como el contacto con los animales o el trabajar la tierra ${ }^{79}$.

El propio Cunninghame Graham se insertaba, así, en la ecuación modernidad/antimodernidad que tanto interesaba en su época, y al hacerlo recibía y a la vez reforzaba una imagen del mundo hispano vinculada a la segunda parte de aquella ecuación. Cabe destacar que en toda esta labor había una llamativa ausencia de escrúpulos geográficos o temporales: como vemos en los testimonios que lo retratan indistintamente como un gaucho argentino y como un hidalgo español, se juntaban alegremente características presuntamente españolas con características presuntamente latinoamericanas, y mitos del siglo XVI con mitos del siglo XIX. Esto era, por otra parte, típico de un contexto intelectual que creía en la existencia de "razas" transnacionales (la literatura de los años del Desastre también hace referencias a las presuntas características de la "raza anglosajona", que se extendería desde Gran Bretańa a los Estados Unidos y Australia); y el propio Cunninghame Graham parece haber participado de estas ideas, puesto que "para él todo el orbe de habla castellana era Hispania" ${ }^{80}$.

En todo caso, pocos aspectos atestiguan la dimensión de Cunninghame Graham de icono de la hispanidad como las numerosas representaciones pictóricas

77 Taylor, People's Laird, p. 295.

78 El Sol, 14 de abril de 1933.

79 De nuevo vemos que el propio Cunninghame Graham contribuía a esta identificación: la gran mayoría de protagonistas, tanto en su obra de ficción como en sus libros históricos, son hombres; Taylor, People's Laird, p. 102.

80 Pérez de Ayala, Amistades y recuerdos, p. 120. 
que se hicieron de él a lo largo de su vida. Estos retratos solían enfatizar algún aspecto de su figura o personalidad que guardara relación con el mundo español o latinoamericano, según las características que ya hemos visto. William Rothenstein, por ejemplo, lo retrató como un espadachín, listo para entrar en acción, en tonalidades ocres (Imagen 1). John Lavery reforzó la asociación con el mundo hispano, titulando su retrato de cuerpo completo "Don Roberto: Commander for the King of Aragon in the Two Sicilies" (Imagen 2). También lo retrató más adelante vestido de gaucho y subido a su caballo favorito, "Pampa" (Imagen 3). El efecto de estos retratos a la hora de reforzar su iconicidad se desprende del comentario de George Bernard Shaw al verlos: "He is, I understand, a Spanish hildago, hence the superbity of his portrait by Lavery (Velasquez [sic] being no longer available)" ${ }^{1}$. La cosa llegó a tal extremo que, en 1902, el artista escocés William Strang pidió a Cunninghame Graham que fuese su modelo para una serie de aguafuertes de escenas del Quijote (Imágenes 4 y 5 ) $^{82}$. Es revelador que todos estos retratos "hispanizados" fueran obra de pintores británicos: el retrato que le hizo Ignacio Zuloaga, por ejemplo, lo representa vestido como cualquier burgués de su tiempo, sentado en una silla con traje de chaqueta cruzada, camisa y pajarita.

La dimensión icónica de Cunninghame Graham también tuvo una vertiente literaria. Su figura inspiró a muchos de sus amigos escritores, y se convirtió en el modelo de varios personajes de ficción. De nuevo, lo que nos interesa es que casi todos esos personajes tenían alguna vinculación con el mundo hispano ${ }^{83}$. Es el caso de Don Carlos Gould en Nostromo, la novela que Joseph Conrad ambientó en Sudamérica; Gould es de familia británica pero nacido en la república ficticia de Costaguana, donde debe asumir la explotación de una mina de plata cuando la hereda -junto a cuantiosas deudas- de su padre. La identificación de Cunninghame Graham con este aventurero de herencia y nacionalidad híbridas (a caballo entre Reino Unido y el mundo hispano), lastrado por deudas familiares y caracterizado por una tenacidad y un sentido del honor fuera de lo común, fue tan fuerte que durante muchos años la edición de Penguin Books de esta novela utilizó como imagen de portada el retrato de Cunninghame Graham realizado por Lavery.

Otro escritor que se vio inspirado por la figura de Cunninghame Graham fue el dramaturgo George Bernard Shaw, quien pudo haber basado hasta cinco personajes de sus obras en quien fue su amigo ${ }^{84}$. El más relevante de ellos para

81 John Lavery, The Life of a Painter. Londres: Cassell \& Co., 1940.

82 Taylor, People's Laird, p. 279.

83 La excepción aquí parece haber sido el personaje de Don Collar Kelleg, el protagonista de Ford Madox Ford en An English Girl (1907); Taylor, People's Laird, p. 279. El personaje sin duda guarda paralelos con Graham, pero vinculados a una naturaleza idealista que en ningún momento se llega a "nacionalizar", es decir, a explicar como propia de un país en concreto.

84 Serían, respectivamente, Sergius Saranoff en Arms and the Man (1894); el capitán Anderson 
este trabajo es John Tanner, el protagonista de Man and Superman, obra escrita en 1903 y representada por primera vez en 1905. Tanner es un británico cuyo carácter rebelde e intrépido lo lleva a huir de Londres y acabar en una Andalucía hecha a la medida de Cunninghame Graham: por un lado, está llena de gitanos y ladrones; por el otro, éstos muestran una excepcional cortesía y una gran conciencia política, dedicando horas enteras a debatir los pros y los contras del anarquismo, del socialismo revolucionario, de la socialdemocracia... El vínculo entre el aventurero Tanner y el mundo español queda reforzado en el famoso tercer acto de la obra, cuando el protagonista se transforma en Don Juan -las acotaciones indican que el mismo actor debe dar vida a Tanner y al personaje de Tirso-, desciende a los infiernos y mantiene una larga conversación con Mefistófeles. En el transcurso de esta conversación, Don Juan recuerda en varias ocasiones la dominación musulmana de la Península Ibérica.

Cunninghame Graham no supuso únicamente, por tanto, el modelo para un intrépido personaje que vive aventuras en España, sino que ofreció a Shaw algunas de las claves para su reinterpretación del mito de Don Juan y, a través de él, para una de las apropiaciones más originales del mismo realizadas en un contexto anglosajón $^{85}$. Una apropiación que, a su vez, tuvo influencia: las tesis de Shaw son importantes para entender el estudio de Maeztu Don Quijote, Don Juan y la Celestina (1925). A pesar de que éste nunca haga referencia a Man and Superman, no parece casualidad que empiece citando el mismo poema que da título al tercer acto de la obra de Shaw, esto es, el "Don Juan aux enfers" de Charles Baudelaire ${ }^{86}$. Además, Maeztu coincide en algunas de las tesis de Shaw acerca del personaje de

y Dick Dudgeon en The Devil's Disciple (1897); el capitán Brassbound de Captain Brassbound's Conversion (1899); John Tanner en Man and Superman (1903); y Hector Hushabye en Heartbreak House (1919). Ver R. Weintraub, "Don Roberto in Bernard Shaw's Plays", en SHAW. The Annual of Bernard Shaw Studies, vol. 31 (2011), pp. 149-155. En algunas de estas obras, la propensión de Graham a la aventura y al viaje hace que parte de la acción suceda en países extranjeros: Estados Unidos en The Devil's Disciple, Bulgaria en Arms and the Man, y Marruecos en Captain Brassbound's Conversion. España sólo aparece en Man and Superman.

85 Es posible que algo parecido sucediera en el caso de otra de las grandes apariciones de un mito literario español en la literatura británica de la época: me refiero al acercamiento de Chesterton al Quijote en The Return of Don Quixote (1927). Chesterton, como se ha visto, conoció a Cunninghame Graham y se sintió atraído por su figura; y es posible que la romantización que realiza el protagonista de su novela de la Edad Media guarde algún paralelismo con el socialismo medievalista que predicaba Cunninghame Graham. Sin embargo, ahí acaban los paralelos, y es cierto que el propio Chesterton cultivaba un medievalismo de su propia cosecha. Chesterton no cita en ningún momento de su Autobiografía a Graham como inspiración literaria, ni tampoco hace referencia a él en los artículos que escribió acerca de España, ni he visto señalada en las biografías de Chesterton a las que he tenido acceso la posibilidad de que Graham fuera el modelo para el protagonista de The Return of Don Quixote.

86 Ramiro de Maeztu, Don Qujote, Don Juan y la Celestina: ensayos en simpatía. Madrid: Visor Libros, 2004, p. 89 
Tirso, como por ejemplo en la idea de que Don Juan no es un ateo sino alguien que cree en la existencia de un infierno, pero prefiere no pensar aún en él; y su idea acerca de la apropiación de Don Juan por parte de no-españoles ("los extranjeros no conciben a Don Juan como al burlador, sino como al buscador de ideal") se ajusta al Don Juan contemplativo y creyente en la "Fuerza Vital" de Man and Superman ${ }^{87}$. Sin poder desarrollar demasiado este punto, es probable que la ausencia de referencias a Shaw en los ensayos de Maeztu acerca de Don Juan se deba al profundo rechazo que generó en el vitoriano la actitud pacifista de su otrora ídolo durante la Gran Guerra ${ }^{88}$. En todo caso, nos damos cuenta de la peculiar bidireccionalidad que puede llegar a tener la influencia cultural: Cunninghame Graham inspira a George Bernard Shaw a revitalizar el interés por Don Juan en la literatura británica, y esta apropiación estimula a su vez las reflexiones de los españoles acerca de su propia tradición literaria.

\section{Conclusión}

Robert Cunninghame Graham fue uno de los mediadores culturales entre España y Reino Unido más importantes y polifacéticos de su tiempo. Por un lado, desarrolló una interpretación del imperio español que rehabilitaba a éste de la "leyenda negra" acumulada por una larga tradición historiográfica, con lo que esto significaba en una época que creía que el "carácter nacional" se mantenía inmutable a lo largo de los siglos. Esta rehabilitación tenía sus tensiones, sus parcialidades y sus ambigüedades, reflejando fielmente un contexto ideológico que intentaba equilibrar una visión crítica del imperialismo británico con un relativismo histórico y una continuidad de ciertos estereotipos acerca de los pueblos no-europeos. Además, Cunninghame Graham vinculó a España con una épica y una estética de la antimodernidad que la hacían atractiva para aquellos de sus compatriotas que rechazaban el mundo capitalista e industrial.

En paralelo a esto, el autor facilitaba la creación de contactos entre escritores y artistas de ambos países. Aquella labor fue importante para una serie de figuras de las letras españolas que buscaron conocer mejor uno de los países más desarrollados de Europa, en el marco de proyectos intelectuales como el europeísmo o el regeneracionismo. También contribuyó a que varios británicos se interesaran por España. Finalmente, Cunninghame Graham ejerció como una suerte de icono de la hispanidad, atrayendo una serie de estereotipos culturales preexistentes a la vez que contribuía a su difusión y fortalecimiento. Lo interesante, tanto en este

87 La cita de Maeztu, en Don Quijote..., p. 103.

88 Un rechazo que aún resulta palpable en las páginas de Don Quijote, Don Juan y la Celestina. Maeztu declara que "En medio de la contienda europea sońé más de una vez ante las líneas enemigas con que los buenos soldados del otro lado de la loma se unieran a los de éste, y todos juntos, ingleses, franceses, alemanes y belgas se volvieran contra los pacifistas y aprovechadores de retaguardia”. Maeztu, Don Quijote..., p. 96. 
caso como en el de sus escritos acerca de España, es la utilidad política y estética que para ciertas corrientes ideológicas tenía una España vinculada a un pasado premoderno. El caso de Cunninghame Graham nos muestra, así, la polivalencia del mediador cultural y la complejidad de las motivaciones que pueden llevarlo a desempeñar su papel.
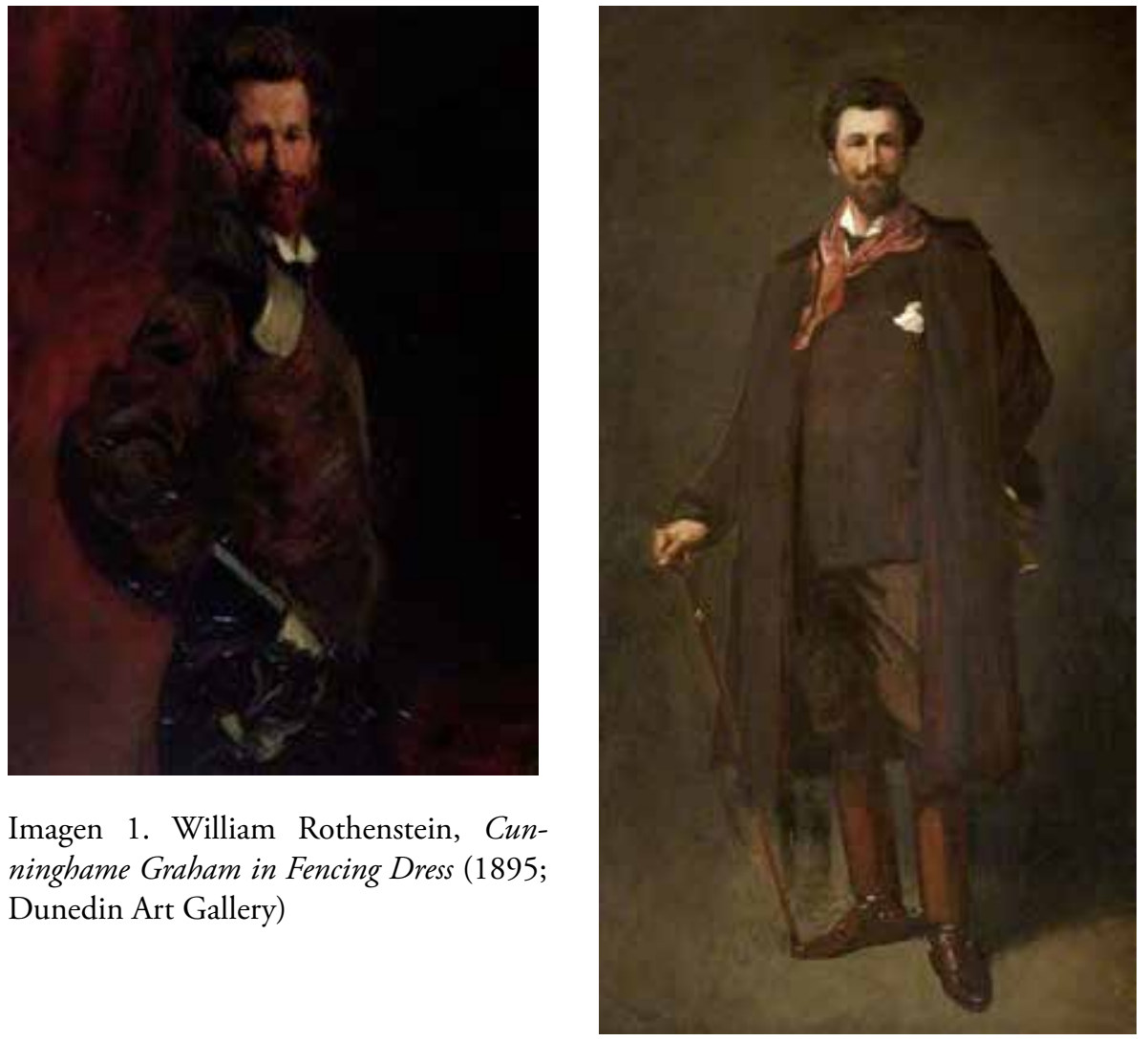

Imagen 1. William Rothenstein, Cunninghame Graham in Fencing Dress (1895; Dunedin Art Gallery)

Imagen 2. John Lavery, Don Roberto: Commander for the King of Aragon in the Two Sicilies (1893, Kelvingore Art Gallery and Museum) 


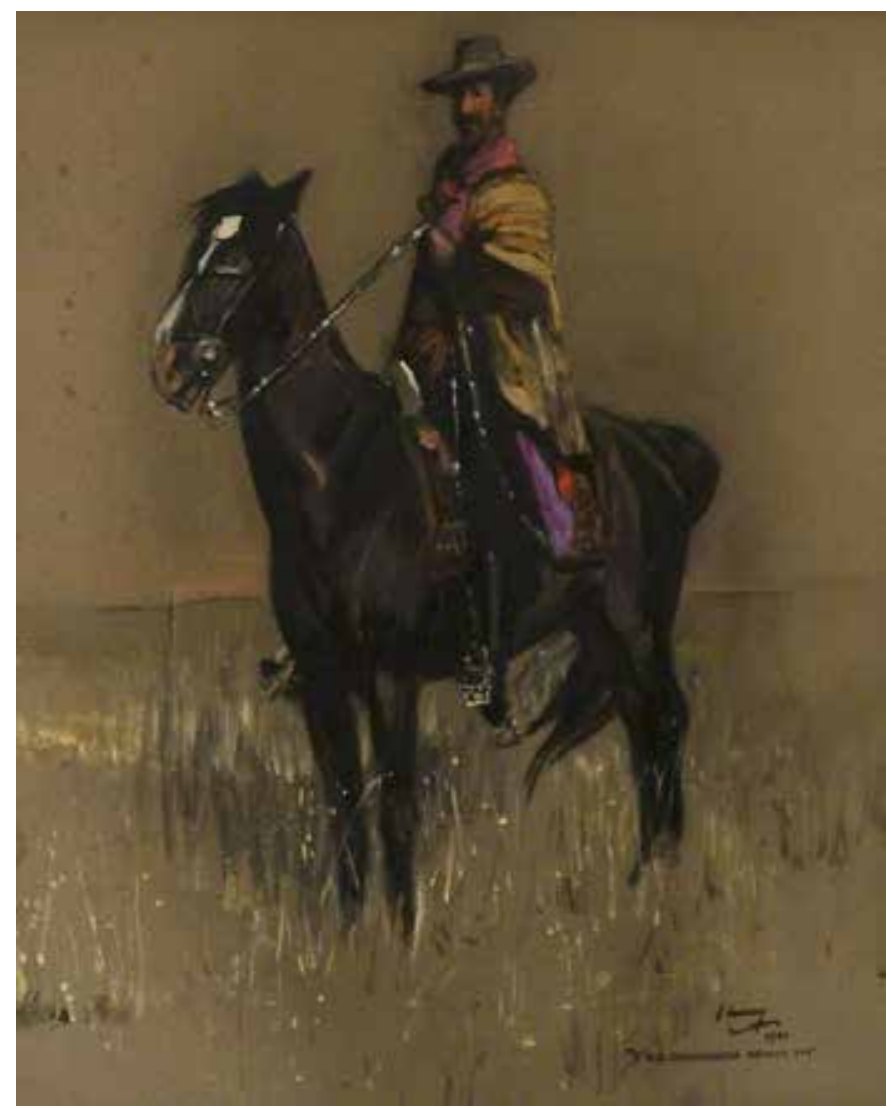

Imagen 3. John Lavery, R. B. Cunninghame-Graham of Ardoch on His Argentinian Pony (1901, The National Trust for Scotland, Culzean Castle, Garden \& Country Park) 


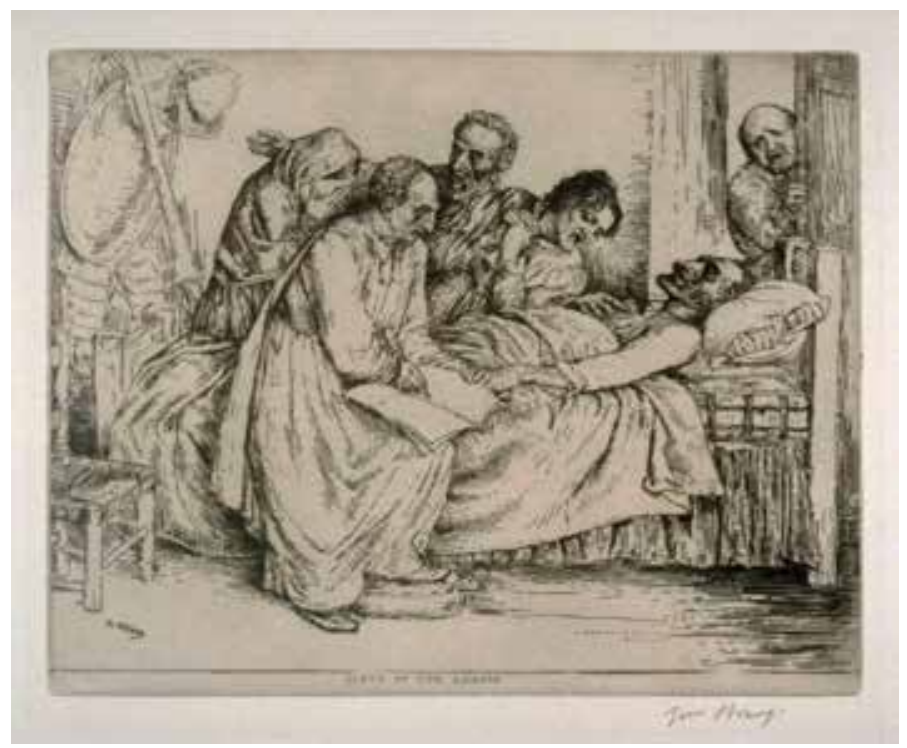

Imagen 4. William Strang, A Series of Thirty Etchings by William Strang Illustrating Subjects from 'Don Quixote' (Londres, Macmillan and Co., 1902)

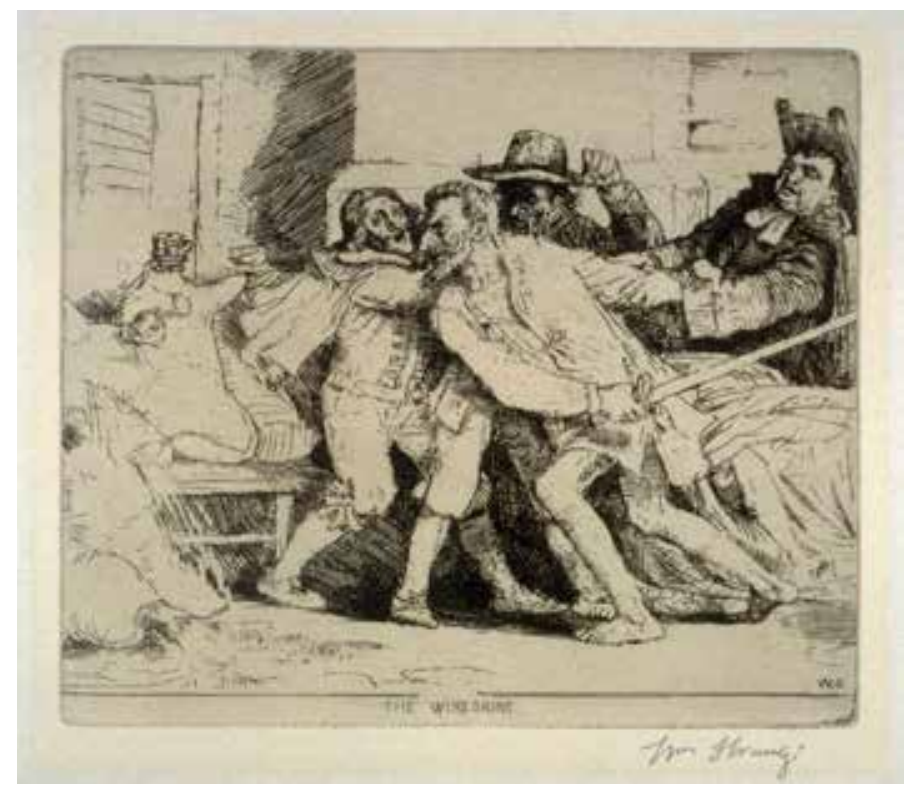

Imagen 5. William Strang, A Series of Thirty Etchings by William Strang Illustrating Subjects from 'Don Quixote' (Londres, Macmillan and Co., 1902) 
